\title{
What makes weird beliefs thrive? The epidemiology of pseudoscience
}

\author{
Maarten Boudry, Stefaan Blancke, and \\ Massimo Pigliucci
}

What makes beliefs thrive? In this paper, we model the dissemination of bona fide science versus pseudoscience, making use of Dan Sperber's epidemiological model of representations. Drawing on cognitive research on the roots of irrational beliefs and the institutional arrangement of science, we explain the dissemination of beliefs in terms of their salience to human cognition and their ability to adapt to specific cultural ecologies. By contrasting the cultural development of science and pseudoscience along a number of dimensions (selective pressure, cumulative change, sources of stabilization, and types of attraction), we gain a better understanding of their underlying epistemic differences. Pseudoscience can achieve widespread acceptance by tapping into evolved cognitive mechanisms, thus sacrificing intellectual integrity for intuitive appeal. Science, by contrast, defies those deeply held intuitions precisely because it is institutionally arranged to track objective patterns in the world, and the world does not care much about our intuitions. In light of these differences, we discuss the degree of openness or resilience to conceptual change (evidence and reason), and the divergent ways in which science and pseudoscience can achieve cultural "success".

Keywords: Belief Systems; Content Biases; Cultural Attractor; Cultural Evolution; Cultural Stability; Defense Mechanisms; Epidemiology; Intuition; Pseudoscience

\section{Introduction}

The past couple of years have witnessed a renewed interested in the demarcation project (Gordin, 2012; Pigliucci \& Boudry, 2013). Modern approaches to demarcationism have abandoned the narrow and strictly formal approach of traditional solutions, which are now seen as suffering from severe problems. In the wake of the insight that there is no

\footnotetext{
Maarten Boudry is a postdoctoral research fellow at Ghent University. Stefaan Blancke is a postdoctoral research fellow at Ghent University. Massimo Pigliucci is K.D. Irani Professor at the City College of New York.

Correspondence to: Maarten Boudry, Department of Philosophy and Moral Sciences, Ghent University, Blandijnberg 2, Room 0.128 9000, Ghent, Belgium. Email: maartenboudry@gmail.com
} 
such thing as a formal and content-free "scientific method," philosophers have been forced to rethink the boundaries between science and other epistemic endeavors. Instead of pursuing the formalist "silver bullet" approach to definitions, centered around a small number of necessary and jointly sufficient conditions, these new demarcation accounts have incorporated cognitive, psychological, and sociological elements in their description of science and pseudoscience.

The study of pseudoscience has received new impetus from burgeoning psychological research on the roots of supernatural belief, superstition, and other forms of irrationality (Blancke \& De Smedt, 2013; Hutson, 2012; Talmont-Kaminski, 2013). In the study of religion, notably, researchers have already made considerable headway exploring the cognitive roots of supernatural belief (Barrett, 2007; Boyer, 2001). Formal models have been developed for extending those insights to the cultural level, explaining how certain forms of belief resonate with our shared psychological makeup, and hence are more readily distributed and disseminated. Psychology and cognitive science, from this perspective, bear on the study of human culture in a way akin to how physiology and immunology bear on the epidemiology of diseases (Sperber, 1996).

Pseudoscience, as the etymology of the word suggests, is a form of imitation or fakery. It exhibits the superficial trappings of science, but all it offers is epistemic fool's gold. Despite their superficial resemblance, science and pseudoscience are radically different. These differences translate into distinct epidemiological dynamics. Evolutionary models of science have been developed before, but comparisons with pseudoscience are rare, even in sophisticated and extensive accounts (Hull, 1990). To understand how scientific knowledge is acquired, and how epistemic progress in science is possible, it is instructive to have a look at practices that are widely regarded as falling short of science, despite their pretensions. In this paper, we examine the difference between the cultural evolution of bona fide science and pseudoscience (see Mesoudi, 2011 for a discussion of cultural evolution). Earlier, we have developed a psychological and epidemiological model for the cultural dissemination of irrational beliefs (Boudry \& Braeckman, 2012; for a discussion of the epidemiological model, see Sperber, 1990). By contrasting the cultural development of both types of beliefs along a number of dimensions (degree of cumulative change, source of stability, and type of cultural attractors), we gain a better understanding of the conditions under which evolutionary approaches are fruitful for understanding the emergence of cultural design. Let us start with a brief account of the cultural evolution of science and then move on to pseudoscience, the main focus of this paper.

\section{Cultural Evolution of Science}

\subsection{Epistemic Selection}

Most of the time, we like to think that we have good reasons for holding some belief about the world. Many everyday beliefs have earned their place in our stock of 
knowledge-or so we think-because they are true, sometimes obviously so. Ever since the early scientific advances of antiquity, and in particular since the scientific revolution in the seventeenth and eighteenth centuries, we have devised methods to arrive at less obvious truths about the world. Though the process of scientific discovery is much more complicated, the basic goal of science is no different from the acquisition of everyday beliefs: we seek knowledge and try to weed out falsehood.

In science, this process of selection and retention is played out over many different rounds and produces gradual cultural change, at first in the scientific community but eventually also in the population at large, insofar as scientific knowledge trickles down to the public. The parallels between the historical development of science and biological evolution by natural selection have been noted before (Hull, 1990; Popper, 1980; Toulmin, 1967). In particular, Stephen Toulmin argues that an evolutionary approach to science resonates with what Popper perceived as the "cardinals virtues of science," i.e., freedom of conjecture and severity of criticism: "Freedom of conjecture enlarges the available pool of variants: severity of criticism enhances the degree of selective pressure" (Toulmin, 2009, p. 188).

Evolutionary models, however, are neutral with respect to which selective pressures are operative and what is their respective strengths. In an epistemically ideal environment, empirical evidence and genuine conceptual puzzles exert the dominant influences on competing representations. In other endeavors, such as religion, politics or pseudoscience, the selective pressures may be very different. Indeed, even in science, despite the so-called "Legend" that is sometimes promulgated (Kitcher, 1993), epistemic considerations form only one among several selective pressures at play (Campbell, 1987, 1997). What makes science interesting from the evolutionary perspective is that its social and institutional organization, as well as its professed ethos and methodology, are fashioned in such a way that epistemic selection pressures (both empirical and conceptual) are amplified while others are suppressed. As David Hull writes, with regard to the ideal of objectivity in science:

The objectivity that matters so much in science is not primarily a characteristic of individual scientists but of scientific communities. Scientists rarely refute their own pet hypotheses, especially after they have appeared in print, but that is all right. Their fellow scientists will be happy to expose these hypotheses to severe testing. (1990, pp. 3-4)

The fact that scientists, as all human beings, suffer from confirmation bias and a host of other foibles need not be detrimental to the progress of science (Goldman, 1999; Hull, 1990). The rationality of science emerges from its social organization-only in rare cases is it exemplified in the reasoning of a single individual (Darwin comes to mind). Science co-opts the baser motives of human behavior in the service of truth, making sure that collective interests mostly align with epistemic progress: "Factionalism, social cohesion, and professional interests need not frustrate the traditional goals of knowledge-acquisition" (Hull, 1990, p. 26). Institutional arrangements provide selfish motives for honesty and truthfulness in reporting and sharing results with others (Campbell, 1997; Goldman, 1999; Haack, 2007). If the right 
institutional structures are in place, then we may expect science to advance, by dint of collective decision, in the direction of better and more accurate theories. As Donald Campbell notes:

\begin{abstract}
A selectionist model for a scientific belief "justifies" such a belief to the extent that it is plausible that "the way the world is" has participated as one of the systematic selectors of that belief from among the historically developed rival beliefs. Spelling this out will lead to rather orthodox conclusions: experimentation is important as, too, are competitions in the prediction of natural (e.g., astronomical) events. The ideology of the 17th century scientific revolution held out as an ideal socialconstruction system that would plausibly increase the role of selection of scientific beliefs by their presumed referents. (1997, p. 12)
\end{abstract}

The social structure of science reflects a phenomenon that psychologists call the "assembly bonus effect," whereby a group of people achieve better cognitive performance than each individual member would alone (Laughlin, VanderStoep, \& Hollingshead, 1991). The scientific worldview is a product of collective, cultural design. In some cases, single individuals take great leaps forward, but even their achievements would not have been possible without the collective work of their predecessors. Even geniuses need the shoulders of other giants to stand on. Moreover, brilliant ideas need skillful defenders and promoters to win over the scientific community. As much as many scientists work in relative isolation, sooner or later they need to face the severe "selection" routines of their fellow experts.

Evolutionary models of science gain traction because of the collective nature of scientific activity and the cumulative growth of scientific knowledge, which surpass the cognitive capacities of any individual scientist. Fallible though this process of epistemic selection might be, there can be no doubt that it has bred impressive success. Darwin's theory prevailed in the end because he and his supporters had arrayed such a wealth of evidence on its behalf. As Hull documents, "time and again scientists end up refuting the very views that they set out to support" (1990, p. 294). For example, even though early geneticists were opposed to the material conception of the gene, their own findings eventually pulled them in that direction (Hull, 1990, p. 57). The theory of phrenology, by contrast, was driven to cultural "extinction" because, in the end, it could not withstand the rising tide of empirical and conceptual difficulties. Only the staunchest social constructivist would deny that long-running trends in the history of science reflect the way the world out there really is.

If one dares to take a closer look at the nitty-gritty practice of science, it may seem amazing how much progress has been made. In some way, eventually, truth is vindicated and falsehood weeded out, but the road is bumpy and arduous. Detailed reconstructions of episodes in the history of science typically reveal a messy process, with lots of detours and backtracking. Consider some of the cognitive biases and foibles that the institutions of science have to guard against. Many natural endowments of human cognition seem ill suited to the dispassionate pursuit of science. Confirmation bias clouds our reasoning, intuitions lead us astray, and emotional attachment prevents us from viewing the world as it is. Throw in the power 
of dogma, orthodoxy, jealousy and petty rivalry, and it begins to look surprising that any progress has been made at all.

Full-blown science has only been developed once in the history of humanity (with early preludes in ancient Greece and the Arab world during the middle ages), and continued progress is far from guaranteed (Haack, 2007). In addition, parts of reality may be forever beyond our reach, because of innate cognitive limitations. The history of science may be viewed in terms of a struggle between epistemic selection pressures and the aggregate forces of personal and social bias. Especially when evidence is weak or ambiguous, or when the methods of investigation are insufficient to discriminate between different hypotheses, non-epistemic noise may easily drown out the timid whisperings of nature.

\subsection{Content Biases and Intuitions}

Evolutionary theorists have distinguished between content biases and context biases acting on the dissemination of representations. Examples of context biases include the tendency of people to preferentially adopt the beliefs of prestigious individuals, known as the prestige bias (Richerson \& Boyd, 2005). The conformist bias, by contrast, describes our inclination to accept the most commonly held representation in a community. In the history of science, the negative effects of these biases include the reign of orthodoxies, the inertia of scientific paradigms or research programs (e.g., Bowler's 1992 work on the Darwinian eclipse), and undue deference to the judgment of eminent scientists (Hull, 1990; Kuhn, 1962). In some instances, context biases stall the progress of science, and may take a generational shift for science to overcome. Max Planck famously quipped that science advances one funeral at a time, though others argue that this is the exception rather than the rule (e.g., Thagard, 1992).

The second type of transmission biases concerns the preferential adoption of beliefs on the basis of their content. Human minds are not blank slates. Biological evolution has endowed us with an intuitive conception of the world, carved around distinct ontological categories (inanimate objects, living things, agents), each coupled with respective intuitions and assumptions (Spelke \& Kinzler, 2007). These conceptual frameworks, which are sometimes referred to as folk physics, folk biology, and folk psychology, are cross-culturally stable and probably a basic feature of our psychological makeup. Modern science, however, has not been particularly kind to this intuitive worldview. Many scientific theories run roughshod over our deepest intuitions. An indirect though reliable indicator of the growth of knowledge is that science has been demonstrably successful in overcoming many of these intuitive biases. Lewis Wolpert puts the point forcefully: "I would almost contend that if something fits with common sense it almost certainly isn't science” (1992, p. 11). It is not so much that reality is always inimical to our intuitions (it's nothing personal, strictly business). It's just that, so to speak, it does not care a whit about them. Robert McCauley writes:

Science challenges our intuitions and common-sense repeatedly. With the triumph of new theories, scientists and sometimes even the public must readjust their 
thinking. When first advanced, the suggestions that the earth moves, that microscopic organisms can kill human beings, and that solid objects are mostly empty space were no less contrary to intuition and common sense than the most counterintuitive consequences of quantum mechanics. (2000, p. 69)

From the viewpoint of cultural evolution, this places scientific beliefs at a disadvantage. Intuitive beliefs are easier to grasp and remember, and less susceptible to decay and distortion through transmission. The modern theory of evolution by natural selection, for example, is profoundly counterintuitive. Intuitive folk biology invites us to think about species in terms of definite categories with an immutable essence. Population thinking, by contrast, which came to supersede essentialism in biology, views species as loose aggregates of individuals showing a certain distribution of characteristics rather than an immutable set of properties. Moreover, the creative power of blind selection also conflicts with our teleological intuitions about functional complexity and our intuitive design stance (De Cruz \& De Smedt, 2010; Kelemen \& Rosset, 2009; Reiss, 2009). The resistance against evolutionary theory is not likely to go away anytime soon. Even among those who embrace it, including biology teachers, misconceptions about the theory remain prevalent (Gregory, 2009). Distortions are typically in line with intuitive conceptions. As Richard Dawkins notes, "it is almost as if the human brain were specifically designed to misunderstand Darwinism, and to find it hard to believe" (1996, p. xv). Examples from other disciplines of science abound. Principles of folk physics, such as the impetus theory of motion, are in direct conflict with our scientific understanding of physical inertia, and even students of physics can be caught falling back on their old intuitive misconceptions (Brown, 1987; Clement, 1993).

Without the elaborate institutional support and prestige from which it benefits in our culture, science would probably soon collapse. In the global marketplace of ideas, writes McCauley (2000), science has "natural disadvantages," given its profoundly counterintuitive nature and its esoteric interests. Despite efforts to reach out at the public at large, many people distort scientific knowledge so as to bring it more in line with their intuitive conceptions of the world. But if science is hard to stomach, why do some people try to actively mimic its outlook and authority? McCauley is primarily concerned with the difference between science and intuitive belief (including folk religion), not so much with beliefs that don the mantle of science. It would be interesting to investigate, however, how science fares in the real world compared to its contenders. The peculiar nature and cultural dynamic of science can be highlighted by contrasting it with belief systems that look similar on the surface, but turn out to be profoundly different.

\section{Evolution of Pseudoscience}

The perspective of cultural evolution, as applied to the history of science, can gain "traction" because of the collective nature and social structure of science (GodfreySmith, 2012), its open-ended character, and its progress through repeated rounds of 
conjectures and criticism. Scientific knowledge is a form of cultural design that emerges out of the complicated interplay of intellectual curiosity, social competition, empirical testing, peer review, and so on.

If we want to develop an evolutionary model of pseudoscience, we should take into account partly different selective pressures. If we accept that the cultural success of pseudoscience is not a function of its epistemic warrant, there must be other factors at play. Strange notions, repudiated by relevant scientific experts, have waxed and waned over the years. The catastrophist theories of Immanuel Velikovsky drew tremendous support among the public at large in the 1950s, but nowadays the name 'Velikovsky' hardly rings a bell with most people, although his cosmic explanations for biblical stories live on in the ancient astronauts hypothesis, which is maintained, for instance, by Erich Von Däniken (Gordin, 2012). Phrenology, once a promising theory taught at major European universities, eventually collapsed under the weight of evidence but persisted long at the fringes of science. Now it seems to have all but vanished (unless one counts some forms of neuroimaging as its latest incarnation; see Satel \& Lilienfeld, 2013). Other pseudosciences, such as astrology or dream interpretation, have been around for millennia.

Note that, although many pseudosciences have a clear affinity with other forms of misbelief, such as superstition, magic, and religion, full-blown pseudoscience requires the existence and prestige of a proper science to serve as a model. For example, it is something of a stretch to treat medieval alchemy and astrology as "pseudosciences," even though they may suffer from similar epistemic problems to the ones we are concerned with here, and would certainly be branded as pseudoscience today (compare Ruse, 2013). From a historical perspective, the category of pseudoscience or "science falsely so-called" arose in the context of disputes over how to delineate the boundaries of newly burgeoning sciences (Gordin, 2012; Numbers \& Thurs, 2013).

What, then, determines the cultural success or failure of a pseudoscience? Many other contingent factors affect the rise and decline of pseudoscientific doctrines, including the charisma of a founder, the vagaries of the political and cultural environment, the dynamics of waxing and waning fads, attention from the press and the public at large, the reaction of the scientific establishment, and so forth (Gordin, 2012). In the rest of this paper, however, we will be concerned with more general factors affecting the evolution of pseudoscience, not so much with the vicissitudes of individual histories. In terms of cultural success, the general problems confronting every pseudoscience include the necessity to appeal to human minds, to mimic the outlook of real science, and to cope with the problem of (or lack of) epistemic warrant.

\subsection{Epidemiology of Pseudoscience}

In Dan Sperber's epidemiological framework of representations, the universal features of our cognitive makeup play an important part in stabilizing representations around "cultural attractors," that is, optimal forms on which representations tend to converge (Sperber, 1996). In science, however, such content biases can disrupt lofty epistemic ambitions, and need to be held in check by the safeguards of controlled 
experimentation, systematic gathering of data, formal modeling, and peer review (McCauley, 2011). In this way, scientific institutions shape a cognitive ecology that radically alters the distribution of representations and makes the cultural attractors shift over time (Heintz, 2007). These shifts are the result of the relatively autonomous dynamic of science, in which novel evidence and criticism steers theory development in particular directions. Of course, science itself is the result of a concerted effort of human brains and would not be possible without intuitions and folk ontologies. In particular, the cognitive makeup of scientists still heavily colors the format and mode of representation of science, as witnessed in the role of metaphors (Brown, 2003), analogies (Gentner \& Jeziorski, 1993), diagrams and symbols, and graphical representations. Despite this continuing reliance on intuitive representations, the substantial content of scientific theories has moved farther and farther away from the cultural attractors fixed by our cognitive makeup. Modern science, even for those who spend a lifetime devoted to it, remains hard to swallow.

Outside the province of science, by contrast, we see beliefs cluster around cultural attractors formed primarily by their intuitive appeal, unfettered by the institutional safeguards and reality checks cultivated by science. In striking contrast with the bulk of genuine science, but in line with much of popular religion, many pseudosciences are intuitively quite palatable. Let us consider a miscellaneous list of our cognitive features — content biases — that provide fertile ground for magic and religion, and then see how they coalesce into pseudoscientific belief systems.

(a) Intuitive essentialism is not only part of our folk biology, but is the default assumption with which the human mind approaches objects, people, and events (Gelman, Coley, \& Gottfried, 1994). From an early age, children assume that invisible essences underlie the observable properties of organisms, social groups, and natural objects. The intuitive appeal of social stereotyping, on the basis of group membership and observable traits, has led to the rise of obnoxious ideologies such as racial pseudoscience. Magic practices and homeopathy (see below) are rooted in essentialist intuitions: belief in the efficacy of traditional medicine is often based on observable similarities or symbolic associations with the afflicted body part, which are presumed to reflect a shared essence. Likewise, the intuitive plausibility of voodoo practices rests on the idea that the invisible essence or soul of a person is transferred to his bodily secretions or possessions, which can be used in turn to affect the person by magical action-at-a-distance.

(b) The human mind is prone to promiscuous teleology, attributing goals to inanimate objects and events while also perceiving goal-directed properties or actions in random noise (Kelemen, 1999a, 1999b). The pervasive influence of this intuitive mode of thinking in religion is well-known: almost every natural occurrence has been interpreted as brought about by supernatural beings, from earthquakes, lightning, rainbows, birth, and death to the origin and design of living beings, the structure of the solar system, and the turn of the seasons. When such religious views are dressed up as science, one gets the various strands of creationism and intelligent design theory, all of which foster our penchant for spotting purposes in natural phenomena. Even outside the domain of traditional religion, however, teleological intuitions have led 
science astray. James Lovelock's still widely popular Gaia theory, for instance, which caught the attention of biologists such as William Hamilton in the 1970s but failed to blossom into mainstream science, is structured around the idea that the course of nature moves towards particular goals.

(c) Related to teleological thinking is our capacity for adopting the intentional stance, a frame of mind that approaches the behavior of an external entity in terms of mental properties, such as desires, beliefs, and motivations. Ever since Heider and Simmel's (1944) elegant demonstrations with moving triangles and circles, we know that this intentional stance is on hair-trigger; abrupt movements, apparently selfpropelled, are sufficient to suggest agency, even if the entity is a simple geometric figure. Error management theory captures the asymmetrical costs involved in detecting agents, particularly when they are adversaries (Galperin \& Haselton, 2012): failing to detect a malicious agent may be potentially lethal (Barrett, 2000). Less obviously, the hair-trigger state of the intentional stance is one of the main cognitive roots of conspiracy thinking (Shermer, 2011), which invariably involves seeing malicious intent in meaningless patterns and coincidences. It also underlies belief in witchcraft and demonic possession.

(d) Humans have a talent for pattern recognition-spotting patterns and correlations in their environment. Again, error management predicts that it is less costly to mistake a spurious correlation for a real causal phenomenon than to mistake a real pattern for a random fluke. Particularly in uncertain environments, with lots of variables and little causal transparency, this bias towards false positives makes people vulnerable to superstition (Haselton, Nettle, \& Andrews, 2005). Numerous pseudosciences and magical belief systems have sprung from this cognitive root, from graphology to phrenology, to dream interpretation, piramidology, telepathy, synchronicity, and astrology.

(e) In everyday communications, at least in a cooperative context, people adopt conversational rules, such as the principle of charity, when trying to interpret what others say (Davidson, 1984). The goal of cooperative communication is to find an interpretation under which the interlocutor's utterance is maximally relevant and true. If your interlocutor seems to be uttering blatant falsehoods or absurdities, it might be useful to consider whether you have misinterpreted his or her utterance. Most people try to make sense when they speak and to tell the truth most of the time. This cooperative principle helps people to overcome the unavoidable ambiguity and noise in every communication. It also makes us prone to overdetect meaning in vague and meaningless statements (Dickson \& Kelly, 1985), and to settle on the first reasonable interpretation we can find as the one that was intended by the speaker. Promiscuous application of this conversational maxim explains the success of cold reading by astrologers and soothsayers (Grice, 1989; Sperber \& Wilson, 1995), and the popularity of horoscopes, fortune cookies, obscure prophecies (e.g., by Nostradamus), and dream interpretation.

(f) The psychological mainspring of medical pseudoscience is placebo thinking (Evans, 2003). People who are ill and believe that they are going to get better, for whatever reason, will tend to get better indeed. This is not a purely psychological 
phenomenon, as it involves demonstrable physiological effects (although the mechanisms are still little understood). In combination with our talent for inferring causation from interesting correlations in our environment, this power of the mind over our body has bred myriad forms of quackery, alternative medicine, spells and sorcery, and voodoo beliefs (McClenon, 2002). The placebo effect also has a negative counterpart, termed the nocebo effect: if you worry that you will get ill or that bad things will happen to you, you may be bringing about your own ill fortune (up to a point). The belief in the efficacy of evil voodoo spells is based on this phenomenon, as are modern-day scares about the health effects of cellphone and Wi-Fi radiation.

Let us now consider a couple of actual pseudosciences in which these content biases are played out. From a cognitive point of view, creationist theories have a considerable edge over modern science. They resonate with our essentialist intuitions about the living world, and they entrench the commonsense view that functional complexity cannot arise out of nowhere or by the mere interplay of chance and necessity (Evans, 2001; Kelemen \& Di Yanni, 2005). They exploit our promiscuous teleology, and of course give full rein to our intentional stance-everything is part of God's plan. Many forms of alternative medicine are based on the intuitive concepts of fluid mechanics (streams of energy, blockades, tensions, impediments) or intuitive statics (restoring of balances between different elements or forces, yin and yang), or rituals of purification and precautions against contamination (cleansing chakras, emptying soul, detoxing). Homeopathy seems plausible in virtue of a number of intuitive biases, in addition to the ubiquitous placebo effect from which all forms of alternative medicine profit. Many homeopathic medicines are diluted beyond the point where there is any molecule of the original substance left. For all intents and purposes, from the point of view of modern chemistry, patients are just swallowing sugar pills or water. Many proponents of homeopathy are aware of this fact but are undeterred; they feel that an intangible essence of the original substance is somehow transferred to the medicine, and that the water molecules retain some sort of memory from having been in contact with the solute. The similia principle of homeopathy, which posits that like should be cured with like, is a form of sympathetic magic, as described originally by James Frazer in The Golden Bough (2004). It is also based on an intuitive principle of antagonism: illness or evil should be fought with the same substance that caused trouble in the first place, or something that represents it. In this way, many people feel that the bad forces cancel each other out-take some hair of the dog that bit you, in other words.

In the history of science, agential explanations have been abandoned in favor of impersonal laws, chance, and other purely natural processes. In pseudoscience, as well as in religion and other supernatural belief systems, explanations in terms of agents (gods, ghosts, witches) or intentional forces (fate, élan vital, karma,) still rule the day. As researchers in the cognitive science of religion have noted, personal explanations of natural events are intuitively very satisfying to the human mind (Barrett, 2007; Guthrie, 1993). We are prone to detecting agency in random or meaningless noise. Although this often translates into supernatural belief systems, as in the case of religion, it may also find expression in conspiracy theories or ufology, which need not involve supernatural agency (Shermer, 2011). 
More importantly, in contrast with religion, not all pseudoscientific belief systems involve intentional explanations. This is partly a matter of arbitrary conventions: if an irrational belief system does not involve (supernatural) agency, we simply don't categorize it as religion, even though it may spring from similar cognitive roots (Boyer, 2001). Belief systems can appeal to human intuitions in many different ways, agential explanations being only one of them. Many forms of alternative medicine, graphology, phrenology, and some parts of parapsychology do not count any intentional agents among their explanatory concepts. For example, the catastrophist pseudo-histories developed by Velikovsky involve explanations for biblical history and world mythology that, at first glance, appear perfectly natural and non-intentional. But consider the kind of physical processes and events Velikovsky was dealing with. Planetary collisions, meteorite rains and super-storms all mesh well with folk physics, involving mundane physical processes that we are all familiar with (precipitation, colliding objects, gravity), which are simply scaled up to cosmic proportions. It is easy to form an intuitive conception of the kinds of events that Velikovsky is portraying. In addition, his epic catastrophes sound appealing to a mind with a preference for stories in which the protagonist faces grave predicaments (Gottschall, 2012). When measured against a modern-day scientific understanding of the physical world, however, such explanations are much more problematic. Then again, modern physics is hard to swallow. The cosmic drama portrayed by Velikovsky is much more palatable than the eerie world of black holes, curved space-time, and geodesic lines of relativistic physics, or even just the inertia principle of Newtonian mechanics.

Many advocates of pseudoscience, as it turns out, actively encourage the reliance on intuition. For example, creationists and intelligent design proponents have openly admitted that the design inference is nothing but a formal elaboration of a common sense intuition about the origins of functional complexity (Blancke \& De Smedt, 2013). In striking contrast with popular science books, which often stress the weird and wayward ways of the world, creationists promote acquiescence in our personal intuitions and encourage distrust of the abstractions and intellectualizations of modern science. Conspiracy theorists, for their part, often express their inner sense of conviction that something is amiss with the received version of historical events, even though they may not be quite sure what it is (Aaronovitch, 2010). Those who believe in past lives, alien abductions, or contact with a spirit world beyond report the same sense of intuitive conviction.

Note that some forms of counterintuitive belief may actually be compelling precisely because they violate our intuitions, provided they do so in the right way. Researchers in the cognitive science of religion have argued that popular religious beliefs, though largely in line with our intuitions, often display a limited but striking violation of our intuitive expectations based on transgressions of ontological categories (Boyer, 1994, 2003). For example, ghosts are in most respects familiar epistemic agents, except for the fact that they are invisible. Talking animals, omnipotent gods, angry trees, and flying witches also conform to this cognitive template. Minimally counterintuitive beliefs, according to Pascal Boyer (2001), exhibit a cognitive optimum. Intuitive violations are salient and attention-grabbing, but when 


\section{M. Boudry et al.}

there are too many of them, the resulting concepts become hard to process and recall. For example, it is hard to make sense of an omnipotent talking tree that exists only when we don't pray to it and that can appear at several places at the same time. Too many intuitions are violated at once. A more homely supernatural concept, such as that of a ghost, has richer inferential potential because it preserves all the familiar properties of agency (memory, emotion, belief, desire) and existence (temporal continuity, spatial location). In combination with minimal violations of mundane agency, such as being invisible or capable of moving through walls, the ghost concept is memorable and suitable for cultural dissemination. To take another example from the domain of the paranormal, psychokinesis is based on the assumption that our mind is capable of moving objects without mediation of our body (Boyer, 2001, p. 77), which (minimally) violates our intuitive expectations and everyday experiences. The role of minimally counterintuitive beliefs in pseudoscience should be explored in further research (see Lindeman \& Aarnio, 2007).

\subsection{The Pull of Reason}

Pseudoscience, as well as many forms of religion, has sacrificed intellectual integrity for intuitive appeal. In science, extremely counterintuitive ideas have won general assent, even among the public at large, in virtue of the epistemic warrant accorded to them. However, a hidden assumption in this argument, which needs to be spelled out more clearly, is that lack of epistemic warrant is a problem in the first place. In evolutionary epistemology, the default assumption is that human cognition is geared towards true belief and reliable inference, especially in ecologically relevant conditions, because those are generally adaptive strategies for getting a firm grip on the world in which the organism needs to survive and reproduce (De Cruz, Boudry, De Smedt, \& Blancke, 2011; McKay \& Dennett, 2009). ${ }^{1}$ Not only are we endowed with perceptual faculties that generally produce an accurate picture of the world, and with reliable inferential strategies and heuristics (Gigerenzer \& Todd, 1999), but it seems that our cognitive orientation towards truth is also mediated by appropriate reward structures. We care about truth. Despite the unflattering picture of human reason that is sometimes painted in popular psychology books, human reasoners are generally sensitive to information that flatly contradicts their personal beliefs (Boudry \& Braeckman, 2012; Gilovich, 1983; Kunda, 1990). This is not too surprising. In a dangerous world, delusions may prove lethal.

Though we are often swayed by prejudice, bias, and wishful thinking, we also like to think of ourselves as generally sane individuals. Researchers in the tradition of motivated reasoning have shown that irrational biases are held in check by how much bigotry, special pleading, and obstinacy we think we can get away with (Kunda, 1990). Being social creatures, we don't like to be regarded as dogmatic simpletons or hotheads. We act like lawyers in defense of our own cognitive sanity. What this means, crucially, is that we cannot do away with reason and evidence altogether. Moreover, in the social context of argumentation, where we try to persuade other people of our beliefs and opinions, we also need to abide by the standards of reasoning upheld by 
those people if we want to increase our chances of influencing them (Mercier \& Sperber, 2011). Because deception and manipulation abound in human communication, people have developed ways to sort out plausible from less plausible information, depending on the content and the source. In a world where only some people are trustworthy and others are manipulative liars or confabulators, it pays to be epistemically vigilant (Sperber et al., 2010).

\subsection{Defense Mechanisms}

Let us focus on the beliefs themselves again. Truth and evidence are selection forces to be reckoned with, because the basic makeup of the human mind (the "host") is geared towards truth. Beliefs that seem reasonable and well supported, other things being equal, have an edge in terms of becoming cultural (i.e., widely disseminated). Beliefs that are epistemically warranted, such as many mundane beliefs in everyday contexts, derive their immediate psychological validation from the blatant evidence in their favor: they are perfectly sensible in virtue of the actual state of the world, given our common perceptual and cognitive resources. Indeed, because they are so "obviously" true, they are rarely even brought under the light of conscious attention (Sperber, 1997), and we don't ponder the reasons for their cultural success. Traditional accounts of knowledge, as Paul Boghossian notes, take for granted that "under the appropriate circumstances, our exposure to the evidence alone is capable of explaining why we believe what we believe" (2006, p. 22).

Established scientific theories, too, owe their cultural stability to the evidence cited in support of them, even though the causal chains leading up to their widespread acceptance are much more convoluted. ${ }^{2}$ People in the twenty-first century accept that science (usually) works due to its many technological applications, and they are quite sensitive to this fact. Science is culturally successful despite the fact that it clashes with some of our most basic intuitions. By and large, people defer to the epistemic authority of science-sometimes begrudgingly_because they admire the technological fruits of science and/or because they know it is reasonable to defer to the expertise of more knowledgeable persons (Sperber, 1996, p. 97). If our best scientific theories did not have solid evidence and technological success to back them up, they would soon wither away, or they would not have risen to prominence in the first place.

Beliefs without epistemic warrant, by their very nature, cannot benefit from the boons of empirical evidence and conceptual rigor in virtue of which scientific beliefs stabilize in a population. Pseudoscience caters to our cherished intuitions, but the world does not care about our intuitions. For belief systems that promise the one and final truth about the world, such as religions and grand ideologies, falsehood and contradiction form a serious concern (Talmont-Kaminski, 2013). Pseudoscience, in particular, mimics the outlook of science and openly boasts of its scientific pretensions, including the deference to evidence and reason. ${ }^{3}$ Epistemic warrant, however, is hard to fake, for the simple reason that it depends on factors outside of our control.

If such beliefs (e.g., in a flat earth) appear blatantly false, other things being equal, they risk cultural extinction-few people will be so foolish as to endorse them. In the 


\section{M. Boudry et al.}

absence of evidence to back them up, they will have to find other ways to survivebe somehow sufficiently appealing and plausible to creatures that are, when all is said and done, still moderately accountable to evidence and reason. If this can be pulled off, pseudoscientific beliefs, now unfettered by the disruptive impact of the world out there, have more freedom to gravitate towards belief contents that are intuitively plausible.

And indeed, as a number of scientists and philosophers have noted, pseudosciences exhibit immunizing strategies that protect them against potential refutations. These theoretical features, a form of cumulative cultural design, can be understood against the backdrop of the psychological premium most of us place on evidence and reason. In falsificationist philosophy of science, strategies to dodge criticism and refutation were narrowly construed in epistemic terms. Popper called them "conventionalist stratagems," while his disciple Hans Albert introduced the analogy with immune systems. Boudry and Braeckman (2011) have provided a general classification of these stratagems, which include conceptual equivocation, the use of multiple endpoints in prediction, conspiracy theorizing, built-in ad hoc clauses, and theory-internal explanations for dissent and resistance to the theory. Talmont-Kaminski (2013) has broadened the framework, distinguishing three types of constraints that can limit the openness of a belief system to critical investigation:

(a) the content of a belief;

(b) the social context, i.e., the various social attitudes that make it less likely that beliefs will be investigated;

(c) the methodological content, i.e., the availability of appropriate tools for investigating claims.

In the case of religion and magic, according to Talmont-Kaminski, all three types of constraints work in concert to protect the belief system. In many cases, the three types are tightly linked. For example, social taboos prohibiting the investigation of beliefs may be derived from the belief system itself.

In the wake of science, we have developed stringent procedures for ruthlessly testing and weeding out false beliefs, including supernatural ones. The methodological context, to adopt Talmont-Kaminski's framework, provides less and less protective cover for belief systems. In turn, the increasing availability of these new methods attests to the weakening grip of supernatural worldviews on our culture. In the old days, critical voices could be suppressed by brute force and intimidation. The very idea of submitting religious truth claims to empirical investigation was sheer blasphemy (an excellent immunizing strategy if there ever was one). In the twenty-first century, however, at least in most secular democracies, there is no longer an inquisition or thought police to stop inquisitive minds-both skeptics and intrepid believers-from investigating the empirical truth claims of religion, for example, with regard to the efficacy of prayer (Benson et al., 2006). Many other ancient belief systems-such as astrology, various forms of alternative medicine, or telepathy-have likewise been exposed to critical scrutiny. In the crossfire of intellectual challenges brought about by the secular age, such belief systems are forced to fall back on other survival tricks—or become marginalized. 
Particularly in the community of scientists and educated lay people, there is a significant epistemic selection pressure against irrational belief systems. As McKay and Dennett wrote in their seminal paper on adaptive misbeliefs, "now that skepticism is ubiquitous, 'practically realistic' myths are in danger of losing whatever effectiveness accounts for their preservation up to now" (McKay \& Dennett, 2009, p. 551).

\subsection{Cheating}

Good science, as we noted, derives its cultural stability from the empirical evidence in its favor. In the case of quantum mechanics, this experimental evidence is so strong that we (reluctantly) abandon even our most deeply held metaphysical and causal intuitions. From the perspective of pseudoscience, however, the use of immunizing strategies has a significant drawback: at one stroke, one risks giving up on a rich source of psychological validation. In science, evidence cannot count as support for a theory unless it is the result of a discriminative test. The idea that the strength of a belief is shown by its openness to investigation is not a wholesale philosophical invention-it is a basic epistemic intuition. If there is no real threat of failure, there is no real test. Heads-I-win-tails-you-lose is not a fair set-up for a game; there's nothing at stake for me, so I'm basically cheating in the game.

Flat-out immunizing strategies are tricky because sometimes people see through the ruse of an impervious belief system. If the protective cover is too transparent, it does not take an academic philosopher versed in Popperian falsificationism for suspicions to be raised. Most people with no stake in the matter understand that, to use Carl Sagan's (1996) example, there is something suspicious about an invisible, immaterial fire-breathing dragon that lives in my garage, but leaves no traces at all. The dilemma facing a system of misbelief is to tap into a spurious source of psychological validation without actually running the risk of refutation. What it needs is a confirmational asymmetry-benefits without risk.

Immunizing strategies can create or augment such an asymmetry of (dis) confirmation (see also Gilovich, 1991 on one-sides events). In some cases, the belief system may simply induce a course of action that is self-validating and forestalls disconfirmation. For example, people may take precautionary measures against imaginary dangers (e.g., in superstitious rituals), the "success" of which convinces them of their validity (Gilovich, 1991). Or they will pursue courses of action that guarantee easy confirmation of their convictions, such as in the contagious spread of witchcraft accusations (Knauft, 1985; Mackay, 1974). In other cases, the belief system proffers ad hoc clauses that diminish the salience of disconfirmations. For example, in Christian mythology, as in many other cultures, whether or not prayers will be answered depends ultimately on the whim of supernatural beings, or other circumstantial factors (Boudry \& De Smedt, 2011). These may include the strength of one's faith, one's moral character, the correct performance of the ritual or prayer, and the alleged plans that god has in mind for a person (for an overview, see Boudry \& Braeckman, 2011). Good immunizing strategies function as insurances against refutation that, rather than being openly displayed, are discretely stored away for emergency cases (Cioffi, 1998). 


\subsection{Internal Disruptions}

The self-sealed nature of pseudoscientific belief systems, combined with their spurious methods for validation, has another downside. Paradoxically, it makes them more liable to internal disruptions and instability. In the absence of epistemic constraints driving internal theory development, it is relatively easy for anyone to change the belief system's content, while leaving its epistemic protection shield intact. Frederick Crews (1986), for example, has noted that psychoanalysis has a centrifugal dynamic, evincing a tendency to spin off ever more rival factions, heresies, and conflicting theories. The bitter rivalries over Freud's legacy, and the internecine warfare among different psychoanalytic schools, can be better appreciated against the backdrop of the self-validating nature of the psychoanalytic method invented by Freud. It was just too easy to come up with something different and equally viable. In the absence of any rational procedure to adjudicate between rival versions, as eventually happens in genuine science, social and ideological influences are given free rein (Boudry \& Buekens, 2011). To the extent that the stability of the belief system is maintained, it is through brute authoritarian force, dogma, and ostracizing of dissidents. In Freud's case, a secret committee had to be established to protect the doctrinal purity of his theory, and dissidents were ruthlessly excommunicated (Crews, 1998). Velikovsky, too, when his enthusiastic supporters started to concoct ever more radical and absurd emendations of his catastrophism, "had to assert his authority to keep the doctrines pure while still insisting on their scientific status" (Gordin 2012, p. 135). This problem of balkanization, as Gordin rightly notes but does not fully explain, "confronts everyone rejected by mainstream researchers" (2012, p. 135). The reason why it confronts every pseudoscientist is that precisely the features that make for a successful pseudoscience-spurious methods of validation and protection against criticism-make it vulnerable to internal upheaval.

In the domain of alternative medicine, this volatile internal dynamic is often played out as an endless series of different versions of the same basic theory, with often increasingly inflated ambitions. Because any apparent benefits of alternative medicine are due to the placebo effect and other cognitive illusions, people soon find out that it does not really matter exactly which medicines one administers (or in which dose), or which therapeutic procedure is followed. Before long, quack procedures are extended to any condition and to all sorts of patients. Theoretical confusion and irresolvable disputes will inevitably ensue. In the history of animal magnetism, practitioners initially wielded special instruments such as metal rods to produce the magnetic field. As time went by, however, it was discovered that such instruments were superfluous, as patients were equally happy without them. Instruments were thus soon abandoned, and the range of applications grew larger and larger. Robert Park sums up the point: "That which is thought by the healer to be the cure is eventually eliminated-with no reduction in effectiveness" (2002, p. 62)

Conspiracy theories deserve special mention in this regard, as they are particularly volatile and liable to centrifugal dynamics. Because the rhetorical appeal of conspiracy 
theorizing consists in exposing all the lies that the gullible public has swallowed and never accepting any official story at face value, the culture of suspicion can easily spiral out of control. Truth seekers are invited to keep upping the ante and to devise more and more elaborate conspiracies, with an ever-expanding circle of accomplices and guilty parties. How does one decide where to stop in this mode of theorizing, if nothing keeps the belief system in check? In the end, conspiracy theorists often turn on themselves, accusing each other either of shrinking away from the full truth, being part of the cover-up, or damaging the cause. In remarkable irony, for example, some 9/11 conspiracy theorists are now convinced that the "no plane" hypothesis (the idea that the Pentagon was hit by a missile and that the real plane was redirected to a secret location) was disseminated by government officials to discredit the 9/11 Truth movement. Defenders of the "no plane" hypothesis, for their part, have accused their somewhat more skeptical colleagues of betraying the cause, or even actively covering up the full scale of the truth. In conspiracy theories, the temptation to "keep on digging" is a hard one to resist, given the paranoid logic of the conspiracy belief structure. Conspiracy theorists have now bred their own (inadvertent) reductio ad absurdum in the form of the bizarre theory developed by bestselling journalist David Icke that the world is run by shape-shifting lizards from another planet.

\section{Conclusion}

Epistemic support and intuitive appeal can be modeled as two inversely correlated and compensatory sources of cultural stabilization. Science, on the one hand, by bowing to the demands of evidence, tends to become hard to swallow for laypeople and even scientists themselves. Without its undeniable technological success, its close interconnectedness, and the institutional support it receives (partly in virtue of those technological rewards), no beliefs as unpalatable as those of modern science would stand a chance in the struggle for influence over human minds. Given the way the human mind works, science is a frail creature indeed. The ultimate source of its remarkable cultural dominance is the world out there, which tends to be pretty stable. Pseudosciences, on the other hand, by tuning in on comfortable intuitive representations of the world, have an edge in terms of popular acceptance. The reason for their success, in spite of their epistemic deficiencies, is their intuitive appeal (and other more local and contingent factors). Pseudoscience has traded intellectual respectability for intuitive allure.

Because the world out there does not care much about our intuitions and desires, however, pseudosciences are exposed to a different threat. In the modern world, the broom of reason has swept away many of the cobwebs of superstition and magic that were so dear to us. To the extent that such beliefs have survived at all, they have evolved protective measures against criticism and empirical reality, often adopting the trappings of science. 


\section{Acknowledgements}

We would like to thank the anonymous reviewers from this journal for their constructive comments, William Bechtel for his helpful editorial suggestions, and Konrad Talmont-Kaminski for commenting on an early draft of this manuscript.

\section{Funding}

This research was supported by the Flemish Fund for Scientific Research (FWO) and by Ghent University (bof13/24j/089), and carried out at the Konrad Lonrenz Institute in Vienna.

\section{Notes}

[1] From an evolutionary point of view, this concern with truth and accuracy makes sense. In order to successfully navigate the world, you need an accurate representation of at least those features of the world that are relevant to your survival and reproduction. Indeed, it turns out that it is hard to find examples of flat-out misbelief that are directly biologically adaptive (McKay \& Dennett, 2009). True belief, ceteris paribus, pays off.

[2] By the time scientific findings trickle down to the public at large, if they do at all, the evidence cited in their favor may be largely obscured. Even scientifically literate laypeople often have no more than an inkling of the empirical evidence supporting the scientific worldview (Sperber, 1996, p. 97). Indeed, only a small minority of scientists has (partial) access to such evidence. But this hardly means that the public acceptance of science has nothing to do with rationality. Deferring to the authority of experts is a most reasonable thing to do.

[3] One complication is that some pseudoscientists disown the term "science" and see themselves as promoting "other ways of knowing." They boast of empirical knowledge, but not of the epithet "science" per se. For an elegant solution to this categorization problem, see Hansson (2009); for additional discussion, see the contributions in Pigliucci and Boudry (2013).

\section{References}

Aaronovitch, D. (2010). Voodoo histories: The role of the conspiracy theory in shaping modern history. New York: Riverhead.

Barrett, J. L. (2000). Exploring the natural foundations of religion. Trends in Cognitive Sciences, 4(1), 29-34.

Barrett, J. L. (2007). Cognitive science of religion: What is it and why is it? Religious Compass, 1(6), 768-786.

Benson, H., Dusek, J. A., Sherwood, J. B., Lam, P., Bethea, C. F., Carpenter, W., ... Jain, M. K. (2006). Study of the therapeutic effects of intercessory prayer (STEP) in cardiac bypass patients: A multicenter randomized trial of uncertainty and certainty of receiving intercessory prayer. American Heart Journal, 151(4), 934-942.

Blancke, S., \& De Smedt, J. (2013). Evolved to be irrational? Evolutionary and cognitive foundations of pseudosciences. In M. Pigliucci \& M. Boudry (Eds.), The philosophy of pseudoscience (pp. 361-379). Chicago: University of Chicago Press.

Boghossian, P. A. (2006). Fear of knowledge: Against relativism and constructivism. Oxford: Oxford University Press. 
Boudry, M., \& Braeckman, J. (2011). Immunizing strategies and epistemic defense mechanisms. Philosophia, 39(1), 145-161.

Boudry, M., \& Braeckman, J. (2012). How convenient! The epistemic rationale of self-validating belief systems. Philosophical Psychology, 25(3), 341-364.

Boudry, M., \& Buekens, F. (2011). The epistemic predicament of a pseudoscience: Social constructivism confronts Freudian psychoanalysis. Theoria, 77(2), 159-179.

Boudry, M., \& De Smedt, J. (2011). In mysterious ways: On the modus operandi of supernatural beings. Religion, 41(3), 517-535.

Bowler, P. J. (1992). The eclipse of Darwinism: Anti-Darwinian evolution theories in the decades around 1900. Baltimore, MD: Johns Hopkins University Press.

Boyer, P. (1994). The naturalness of religious ideas: A cognitive theory of religion. Berkeley, CA: University of California Press.

Boyer, P. (2001). Religion explained: The evolutionary origins of religious thought. New York: Basic.

Boyer, P. (2003). Religious thought and behaviour as by-products of brain function. Trends in Cognitive Sciences, 7(3), 119-124.

Brown, D. E. (1987). Using analogies and examples to help students overcome misconceptions in physics: A comparison of two teaching strategies. (Doctoral dissertation). Available from ProQuest Dissertations and Theses database. (Paper AAI8805897)

Brown, T. L. (2003). Making truth: Metaphor in science. Urbana, IL: University of Illinois Press.

Campbell, D. T. (1987). Evolutionary epistemology. In G. Radnitzky \& W. W. Bartley (Eds.), Evolutionary epistemology, rationality, and the sociology of knowledge (pp. 47-89). Peru, IL: Open Court.

Campbell, D. T. (1997). From evolutionary epistemology via selection theory to a sociology of scientific validity. Evolution and Cognition, 3(1), 5-38.

Cioff, F. (1998). Freud and the question of pseudoscience. Chicago: Open Court.

Clement, J. (1993). Using bridging analogies and anchoring intuitions to deal with students' preconceptions in physics. Journal of Research in Science Teaching, 30(10), 1241-1257.

Crews, F. C. (1986). Skeptical engagements. Oxford: Oxford University Press.

Crews, F. C. (1998). Unauthorized Freud: Doubters confront a legend. New York: Viking.

Davidson, D. (1984). Inquiries into truth and interpretation. Oxford: Oxford University Press.

Dawkins, R. (1996). The blind watchmaker: Why the evidence of evolution reveals a universe without design. New York: Norton.

De Cruz, H., Boudry, M., De Smedt, J., \& Blancke, S. (2011). Evolutionary approaches to epistemic justification. Dialectica, 65(4), 517-535.

De Cruz, H., \& De Smedt, J. (2010). Paley's iPod: The cognitive basis of the design argument within natural theology. Zygon: Journal of Religion and Science, 45(3), 665-684.

Dickson, D. H., \& Kelly, I. W. (1985). The "Barnum effect" in personality assessment: A review of the literature. Psychological Reports, 57(2), 367-382.

Evans, D. (2003). Placebo: The belief effect. London: HarperCollins.

Evans, E. M. (2001). Cognitive and contextual factors in the emergence of diverse belief systems: Creation versus evolution. Cognitive Psychology, 42(3), 217-266.

Frazer, J. G. (2004). The golden bough. Sioux Falls, SD: NuVision. (Original work published 1890)

Galperin, A., \& Haselton, M. G. (2012). Error management and the evolution of cognitive bias. In J. P. Forgas, K. Fiedler, \& C. Sedikedes (Eds.), Social thinking and interpersonal behavior (pp. 45-64). New York: Psychology Press.

Gelman, S. A., Coley, J. D., \& Gottfried, G. M. (1994). Essentialist beliefs in children: The acquisition of concepts and theories. In L. A. Hirschfeld \& S. A. Gelman (Eds.), Mapping the mind: Domain specificity in cognition and culture (pp. 341-365). Cambridge: Cambridge University Press.

Gentner, D., \& Jeziorski, M. (1993). The shift from metaphor to analogy in Western science. In A. Ortony (Ed.), Metaphor and thought (2nd ed.) (pp. 447-480). New York: Cambridge University Press. 
Gigerenzer, G., \& Todd, P. M. (1999). Simple heuristics that make us smart. New York: Oxford University Press.

Gilovich, T. (1983). Biased evaluation and persistence in gambling. Journal of Personality and Social Psychology, 44(6), 1110-1126.

Gilovich, T. (1991). How we know what isn't so: The fallibility of human reason in everyday life. New York: Free Press.

Godfrey-Smith, P. (2012). Darwinism and cultural change. Philosophical Transactions of the Royal Society B: Biological Sciences, 367(1599), 2160-2170.

Goldman, A. I. (1999). Knowledge in a social world. Oxford: Clarendon.

Gordin, M. D. (2012). The pseudoscience wars: Immanuel Velikovsky and the birth of the modern fringe. Chicago: University of Chicago Press.

Gottschall, J. (2012). The storytelling animal: How stories make us human. New York: Houghton Mifflin Harcourt.

Gregory, T. R. (2009). Understanding natural selection: Essential concepts and common misconceptions. Evolution: Education and Outreach, 2, 156-175.

Grice, P. (1989). Studies in the way of words. Cambridge, MA: Harvard University Press.

Guthrie, S. (1993). Faces in the clouds: A new theory of religion. New York: Oxford University Press.

Haack, S. (2007). Defending science-within reason: Between scientism and cynicism. Amherst, NY: Prometheus.

Hansson, S. O. (2009). Cutting the Gordian Knot of demarcation. International Studies in the Philosophy of Science, 23(3), 237-243.

Haselton, M. G., Nettle, D., \& Andrews, P. W. (2005). The evolution of cognitive bias. In D. M. Buss (Ed.), The handbook of evolutionary psychology (pp. 724-746). Hoboken, NJ: Wiley.

Heider, F., \& Simmel, M. (1944). An experimental study of apparent behavior. The American Journal of Psychology, 57(2), 243-259.

Heintz, C. (2007). Scientific cognition and cultural evolution: Theoretical tools for integrating social and cognitive studies of science. (Unpublished doctoral dissertation). Ecole des Hautes Etudes en Sciences Sociales, Paris.

Hull, D. L. (1990). Science as a process: An evolutionary account of the social and conceptual development of science. Chicago: University of Chicago Press.

Hutson, M. (2012). The 7 laws of magical thinking: How irrationality makes us happy, healthy, and sane. Oxford: Oneworld.

Kelemen, D. (1999a). The scope of teleological thinking in preschool children. Cognition, 70(3), 241-272.

Kelemen, D. (1999b). Why are rocks pointy? Children's preference for teleological explanations of the natural world. Developmental Psychology, 35(6), 1440-1452.

Kelemen, D., \& Di Yanni, C. (2005). Intuitions about origins: Purpose and intelligent design in children's reasoning about nature. Journal of Cognition and Development, 6(1), 3-31.

Kelemen, D., \& Rosset, E. (2009). The human function compunction: Teleological explanation in adults. Cognition, 111(1), 138-143.

Kitcher, P. (1993). The advancement of science: Science without legend, objectivity without illusions. New York: Oxford University Press.

Knauft, B. M. (1985). Good company and violence: Sorcery and social action in a lowland New Guinea society. Berkeley, CA: University of California Press.

Kuhn, T. S. (1962). The structure of scientific revolutions. Chicago: University of Chicago Press.

Kunda, Z. (1990). The case for motivated reasoning. Psychological Bulletin, 108(3), 480-480.

Laughlin, P. R., VanderStoep, S. W., \& Hollingshead, A. B. (1991). Collective versus individual induction: Recognition of truth, rejection of error, and collective information processing. Journal of Personality and Social Psychology, 61(1), 50-67.

Lindeman, M., \& Aarnio, K. (2007). Superstitious, magical, and paranormal beliefs: An integrative model. Journal of Research in Personality, 41(4), 731-744. 
Mackay, C. (1974). Extraordinary popular delusions and the madness of crowds. New York: Barnes \& Noble. (Original work published 1841)

McCauley, R. N. (2000). The naturalness of religion and the unnaturalness of science. In F. Keil \& R. Wilson (Eds.), Explanation and cognition (pp. 61-85). Cambridge, MA: MIT Press.

McCauley, R. N. (2011). Why religion is natural and science is not. New York: Oxford University Press.

McClenon, J. (2002). Wondrous healing: Shamanism, human evolution, and the origin of religion. DeKalb, IL: Northern Illinois University Press.

McKay, R. T., \& Dennett, D. (2009). The evolution of misbelief. Behavioral and Brain Sciences, 32(6), 493-561.

Mercier, H., \& Sperber, D. (2011). Why do humans reason? Arguments for an argumentative theory. Behavioral and Brain Sciences, 34(2), 57-74.

Mesoudi, A. (2011). Cultural evolution: How Darwinian theory can explain human culture and synthesize the social sciences. Chicago: Chicago University Press.

Numbers, R. L., \& Thurs, D. P. (2013). Science, pseudoscience, and science falsely so-called. In M. Pigliucci \& M. Boudry (Eds.), Philosophy of pseudoscience: Reconsidering the demarcation project (pp. 121-145). Chicago: University of Chicago Press.

Park, R. L. (2002). Voodoo science: The road from foolishness to fraud. New York: Oxford University Press.

Pigliucci, M., \& Boudry, M. (Eds.). (2013). Philosophy of pseudoscience: Reconsidering the demarcation project. Chicago: University of Chicago Press.

Popper, K. R. (1980). Unended quest: An intellectual autobiography. Glasgow, Scotland: Fontana/ Collins.

Reiss, M. J. (2009). The relationship between evolutionary biology and religion. Evolution, 63(7), $1934-1941$.

Richerson, P. J., \& Boyd, R. (2005). Not by genes alone: How culture transformed human evolution. Chicago: University of Chicago Press.

Ruse, M. (2013). From pseudoscience to popular science, from popular science to professional science. In M. Pigliucci \& M. Boudry (Eds.), Philosophy of pseudoscience: Reconsidering the demarcation problem (pp. 225-244). Chicago: University of Chicago Press.

Sagan, C. (1996). The demon-haunted world: Science as a candle in the dark. New York: Random House.

Satel, S., \& Lilienfeld, S. O. (2013). Brainwashed: The seductive appeal of mindless neuroscience. New York: Basic.

Shermer, M. (2011). The believing brain: From ghosts and gods to politics and conspiracies. New York: Holt.

Spelke, E. S., \& Kinzler, K. D. (2007). Core knowledge. Developmental Science, 10(1), 89-96.

Sperber, D. (1990). The epidemiology of beliefs. In G. Gaskell \& C. Fraser (Eds.), The social psychological study of widespread beliefs (pp. 25-44). Oxford: Clarendon.

Sperber, D. (1996). Explaining culture: A naturalistic approach. Cambridge, MA: Blackwell.

Sperber, D. (1997). Intuitive and reflective beliefs. Mind \& Language, 12(1), 67-83.

Sperber, D., Clément, F., Heintz, C., Mascaro, O., Mercier, H., Origgi, G., \& Wilson, D. (2010). Epistemic vigilance. Mind \& Language, 25(4), 359-393.

Sperber, D., \& Wilson, D. (1995). Relevance: Communication and cognition (2nd ed.). Oxford: Blackwell.

Talmont-Kaminski, K. (2013). Religion as magical ideology: How the supernatural reflects rationality. Bristol, CT: Acumen.

Thagard, P. (1992). Conceptual revolutions. Princeton, NJ: Princeton University Press.

Toulmin, S. E. (1967). The evolutionary development of natural science. American Scientist, 55(4), $456-471$. 


\section{M. Boudry et al.}

Toulmin, S. E. (2009). The evolutionary development of natural science. In M. Ruse (Ed.), Philosophy after Darwin: Classic and contemporary readings (pp. 177-189). Princeton, NJ: Princeton University Press.

Wolpert, L. (1992). The unnatural nature of science. Cambridge, MA: Harvard University Press. 